\title{
DA AGRESSÃO À ASSISTÊNCIA, DA INFRAÇÃO À CORREÇÃO: menoridade e violência urbana (Porto Alegre, 1890-1920)
}

\section{Eliane Cristina Deckmann Fleck*}

Ana Paula Korndörfer**

Aline K. Cadaviz ${ }^{* *}$

Resumo: O artigo aborda a violência urbana, em especial, contra a criança e o adolescente no Rio Grande do Sul, no período compreendido entre os anos de 1890 e 1920, dando destaque para a assistência médico-hospitalar decorrente de violência e para as políticas públicas implementadas para atendimento e recuperação social dos menores infratores. As fontes documentais consultadas, ainda que raramente ofereçam indicações explícitas sobre os motivos que levaram à prática infratora e à internação, permitem inferências através do estabelecimento de relações entre os ferimentos apresentados e os meios empregados para causá-los. Em relação aos maus-tratos e às situações de atentado ao pudor, as constatações se baseiam em denúncias, em registros policiais e na incidência de exames de corpo de delito realizados.

Palavras-chave: violência urbana, menor infrator, política pública, Rio Grande do Sul.

Este artigo tem como objetivo apresentar dados preliminares relativos a práticas de violência urbana, ${ }^{1}$ no período compreendido entre os anos 1890 e 1920, a partir de consulta feita aos acervos do

Doutora em História da América pela Pontifícia Universidade Católica do Rio Grande do Sul (PUC-RS), professora do Programa de Pós-Graduação em História Latinoamericana da Universidade do Vale do Rio do Sinos (Unisinos) em São Leopoldo (RS).

** Bolsista de Iniciação Científica pelo CNPq, na Universidade do Vale do Rio dos Sinos (Unisinos), São Leopoldo (RS).

Artigo recebido em 22 dez. 2004; aprovado em 14 abr. 2005. 
Arquivo Histórico do Rio Grande do Sul, Arquivo Histórico da Santa Casa de Misericórdia de Porto Alegre e do Arquivo Público do Rio Grande do Sul.

A investigação se insere no esforço de avaliar a atuação do Estado do Rio Grande do Sul na definição de políticas públicas, ${ }^{2}$ com destaque para as relativas ao tratamento dado às crianças infratoras e às crianças alvo de violência.

Interessa-nos, sobretudo, avaliar o acompanhamento médico e o tratamento dispensado a estas crianças e adolescentes, através de sua destinação a hospitais, reformatórios ou escolas profissionalizantes. ${ }^{3}$

Em levantamento realizado junto ao Arquivo Histórico da Santa Casa de Misericórdia de Porto Alegre, ${ }^{4}$ constatamos que, considerando a faixa etária compreendida entre o zero e vinte e um anos de idade, $43 \%$ foram classificados como brancos e $57 \%$ foram classificados como sendo de cor preta, parda, morena, indiática, fula e china; e que apenas $4 \%$ das internações podem ser atribuídas a agressões sofridas em decorrência da prática de violência. Na verdade, são raros os registros que têm explicitada a causa da internação como decorrente de violência cometida contra o menor internado, cabendo-nos o estabelecimento de uma provável motivação ou relação entre o uso de arma branca, por exemplo, e cortes profundos relatados nos Livros de Matrícula Geral de Enfermos. ${ }^{5}$

Com relação aos dados levantados junto ao Arquivo Histórico do Rio Grande do Sul, estes apontam para um número significativo de registros que se referem à violência cometida contra meninas, o que se observou tanto nos códices da polícia e nos processos-crime, quanto nas solicitações de exames de corpo de delito por atentado ao pudor, encontrados na documentação analisada.

Cabe observar que os dados sobre os maus-tratos e sobre situações de atentado ao pudor são cercados de muita imprecisão, dado que a grande maioria dos casos não implicava a busca de atendimento médico pelas e para as vítimas. Em razão disso, os dados 
se baseiam, em grande medida, em denúncias ou em registros de atendimentos por lesões traumáticas em hospitais. Além disso, tanto nas situações de crime de defloramento, quanto nas de estupro, o praticante viria a ser processado somente com a formalização de queixa da vítima, ${ }^{6}$ o que nos remete aos processos-crime para o cotejo das informações levantadas nos autos de internação.

Na documentação analisada junto ao Arquivo Público do Rio Grande do Sul, constatamos o elevado índice de crimes de ordem moral e sexual, tais como o rapto, o defloramento e o incesto, seguidos de registros de agressões físicas e de ferimentos decorrentes de conflitos tipicamente urbanos. A constatação de práticas como o incesto, o defloramento e o rapto de menores e a incidência de registros de entrada na Santa Casa que atestam maus tratos e descaso familial nos remete à atualidade e à ocorrência de campanhas de conscientização em relação à permanência de problemas estruturais denunciados por higienistas, médicos, intelectuais, juristas e políticos na virada do século XX para o século XXI.

\section{O desafio da violência: história e atualidade}

No final do século XIX, o Direito Criminal brasileiro estava sob a influência dos postulados da Escola Clássica do Direito Penal e da nova Escola Positivista ou Antropológica.

Na década de 1880, encontrava-se ainda em vigência o Código Criminal de 1830 orientando a definição dos conceitos de "crime" e de "criminoso". "Crime" era definido como "toda ação ou omissão voluntária contrária às leis penais"; "a tentativa de crime"; "o abuso de poder que consiste no uso de poder (conferido por lei) contra os interesses públicos ou em prejuízo de particulares, sem que a utilidade pública o exija"; além da "ameaça de fazer algum mal a alguém" (Tinoco, 1886, p. 9-17).

O início do século XX será marcado pelo debate acerca dos campos de conhecimento do Direito Criminal, o que implicou a reavaliação da ação do Direito na esfera jurídico-penal. Dele 
decorrerá a separação entre aquilo que se chamaria de Criminologia - o estudo do crime e do criminoso - e o Direito Penal - o estudo das penas -, o que teria seus efeitos concretizados no Código Penal que passou a vigorar a partir de 1890, em substituição ao Código Criminal Imperial. Foram determinantes para esta reavaliação, o contexto político marcado pela transição do Império para a República, pelo crescimento da indústria, do comércio e dos serviços e pelo reordenamento urbano e sanitário que, não podendo contemplar a todos, fez crescer uma massa de excluídos e marginalizados desse processo. O ideal da sociedade formada por trabalhadores higienizados e integrantes de uma família passou, então, a ser perseguido por médicos e juristas, entre outros.

Pelo Código Imperial, uma pessoa seria considerada "criminosa" ou "delinqüiente", quando tivesse agido de má fé, ou seja, com o conhecimento do mal e a intenção de praticá-lo. Quanto ao menor, a lei estabelecia que não houvesse imputabilidade até os 14 anos, a não ser que ficasse provado que este havia agido com discernimento. Neste caso, seria recolhido às casas de correção pelo tempo determinado pelo juiz, contanto que não excedesse à idade de 17 anos (Tinoco, 1886, p. 24-28, 30).

Quando o réu era menor de 21 anos, contava com as circunstâncias atenuantes, sendo que se tivesse entre 14 e 17 anos, o juiz poderia impor-lhe as penas de cumplicidade. Além disso, a pena de morte nunca se aplicaria ao menor e a pena de galés deveria ser substituída pela de prisão com trabalho (Tinoco, 1886, p.49-54, 70$71)$.

As preocupações dos juristas nos primeiros anos da República giraram em torno das definições de "quem era o menor" ou então "qual era o seu grau de discernimento e de intencionalidade", extrapolando as discussões que se limitavam ao debate sobre a menoridade.

No geral, uma poderosa corrente de pensamento acreditava, com otimismo e entusiasmo, na força da ciência e no primado da razão humana, que propiciariam o progresso indefinido dentro da 
ordem e a vitória da civilização sobre a barbárie. Esse destino seria promovido pelas novas gerações, que, por isso mesmo, deveriam ser bem cuidadas - no físico e na mente. As crianças das 'classes perigosas', dos muito pobres, deveriam merecer atenção redobrada, instrução básica, cuidados com o corpo, higienização dos costumes, treinamento profissional e disciplina rigorosa. Havia que incutir-lhes o amor ao trabalho, a submissão e obediência aos valores e normas da sociedade, para que se tornassem cidadãos 'úteis a si e à sociedade'. Essas são, de forma simplificada, as bases de uma filosofia filantrópico-liberal-científica, que fundamentaram o primeiro projeto nacional de política pública, voltado para a criança pobre desvalida e desviante.

O Código Penal da República, de 1890, "marca a primeira grande fase de atuação do Estado frente ao menor infrator" ao atacar a questão social da infância infratora em seus aspectos mais fundamentais: "a imputabilidade absoluta; o tratamento diferenciado para menores infratores; os lugares especiais para o recolhimento dessas crianças; a vadiagem infantil, e o comportamento sexual dessas crianças" (Marcílio, 2000, p. 40).

As primeiras estatísticas criminais, elaboradas em 1900, já revelam, segundo Mary Del Priore (1999) que "esses filhos da rua, então chamados de pivettes (sic), eram responsáveis por furtos, gatunagem, vadiagem e ferimentos, tendo na malícia e na esperteza as principais armas de sobrevivência. [...] já sabemos desde o início do século: a rua é um meio de vida".

Adriana de Resende B. Vianna (1999), em seu trabalho $O$ mal que se adivinha: polícia e menoridade no Rio de Janeiro, 19101920, investiga o processo de construção de um personagem social, o "menor" ("menoridade" possuindo sentidos diferentes dos de "infância"), através da atuação da polícia (relação menor - polícia) e da classificação desses indivíduos (o termo "menor" seguido de adjetivos como "vadio", "abandonado", entre outros).

A preocupação com a infância desamparada fica evidenciada na criação de um número considerável de instituições voltadas para 
o seu atendimento no País. ${ }^{7}$ Entre essas instituições, podemos citar o Instituto de Proteção e Amparo à Infância (IPAI), fundado em 1899, no Rio de Janeiro, pelo Dr. Moncorvo Filho; o Instituto Disciplinar de São Paulo (São Paulo); a Escola Premonitória Quinze de Novembro (Rio de Janeiro); a Escola de Menores Abandonados (Rio de Janeiro); a Colônia Correcional de Dois Rios (Rio de Janeiro), e o Instituto João Pinheiro (Minas Gerais).

Segundo Maria Luiza Marcílio (2000, p. 41), o objetivo dessas instituições era proporcionar "uma educação saudável, regeneradora, em um ambiente disciplinar e normatizado, onde se ensinaria particularmente o amor ao trabalho, o culto à pátria, os valores éticos de uma sociedade liberal-burguesa". Essas instituições ensinavam as letras e também algum ofício, para que as crianças, entendidas no período como "matéria facilmente moldável", se transformassem em cidadãos disciplinados e trabalhadores.

O estudo de Esmeralda Blanco Bolsonaro de Moura (1999), Meninos e meninas na rua: impasse e dissonância na construção da identidade da criança e do adolescente na República Velha, destaca a existência não da "infância", mas de "infâncias" ou então de uma "infância multifacetada". Foi em razão disso que médicos e legisladores do início do século 20 criaram instituições de confinamento a fim de transformar as crianças em cidadãos úteis e produtivos. Elas passavam da condição de "menores da rua", do século XIX, para "menores de rua", no século XX.

Ao final do século XX, os defensores da infância brasileira depararam-se com problemas decorrentes dessas infâncias bem distintas: a infância das camadas privilegiadas e a infância desamparada, abandonada, marginalizada. Nas ruas, as crianças deixavam de ser crianças e se transformavam em "menores", em delinqüentes. ${ }^{8}$

O governo republicano gaúcho que assumiu o poder político, em 1889, apresentava feição positivista ao defender que o progresso seria alcançado pelo desenvolvimento industrial, pelo primado da ciência, pela educação e pela moral. Através do livro As artes de 
curar: medicina, religião, magia e positivismo na república riograndense, de Beatriz Teixeira Weber (1999), podemos traçar um panorama da situação da saúde no Rio Grande do Sul durante o governo positivista. Acompanhando a situação nacional, o Rio Grande do Sul apresentava um quadro de propagação de epidemias, falta de serviços de atendimento à população, precariedade de recursos e necessidade de verbas especiais em situações de emergência.

Adotando uma perspectiva positivista, o governo do Estado estabeleceu, na área da saúde, uma postura distinta do restante do país, instituindo a liberdade profissional e religiosa (abertura para práticas alternativas de cura) e posicionando-se como contrário ao que chamava de terrorismo e autoritarismo sanitários (intervenção do Estado em assuntos que consideravam como sendo questões pessoais, como, por exemplo, a saúde).

De acordo com essa postura, as medidas adotadas pelo governo para evitar a propagação de doenças foram restritas, mas, contraditoriamente, este mesmo governo não dispensou o isolamento de doentes e a desinfecção das residências para evitar a propagação de doenças. Segundo a autora, entre os anos de 1895 e 1928, houve, quase todos os anos, casos de difteria, peste bubônica, febre tifóide, varíola, varicela, sífilis e tuberculose. Interessa-nos saber se houve uma preocupação especial por parte do Estado em relação ao combate e prevenção de doenças relacionadas à infância.

O "problema do menor" ocupou a atenção da imprensa e dos parlamentares do Rio Grande do Sul no período de 1950 a 1970, constituindo-se em tema dos mais recorrentes, tanto no que se referia à preocupação em relação às crianças e aos adolescentes desassistidos, quanto em relação à ascendente "trajetória criminosa" decorrente desse abandono. Como bem observou Elmir (2002, p. 360 ), os jornais davam "visibilidade aos menores" ao descreverem "situações particulares de marginalização", enquanto as falas dos parlamentares propunham "soluções para reintegrar esses últimos a um convívio social considerado sadio". 
Ao mesmo tempo em que, na atualidade, psicólogos, sociólogos e educadores têm proposto uma nova ética para a infância, somos constantemente informados do descaso em relação à infância que se traduz no trabalho infantil e na exploração sexual de crianças de ambos os sexos.

Na seção Editoriais do Jornal Zero Hora, de 2 de dezembro de 2004 (p. 20), encontramos a informação:

O que mais surpreende nos dados sobre expectativa de vida divulgados ontem pelo Instituto Brasileiro de Geografia e Estatística (IBGE) não é a continuidade da redução da mortalidade infantil e o aumento de 70,5 para 71,3 anos, de 2000 para 2003, na expectativa de vida. [...] $\mathrm{O}$ que surpreende negativamente é o fato de o país ter avançado nessas áreas e estar perdendo a guerra para a violência, que se constitui hoje no principal impeditivo de um patamar mais elevado de vida para os brasileiros. [...] Informa, por exemplo, que o Brasil por algum tempo experimentou quedas constantes nas taxas de mortalidade em todas as idades, mas que, a partir de meados dos anos 1980, as mortes associadas ao que chama de causas externas, que é maneira eufemística de identificar a violência, passaram a ter um papel destacado. Essas "causas externas" abateram-se pesadamente sobre a população, em particular sobre adultos jovens do sexo masculino $[\ldots]$

Reagindo ao Editorial, o jornalista Júlio Mariani (2004) acrescenta outros dados, como o de que "o assassinato é a principal causa de morte de garotos com idades entre os cinco e os quatorze anos" e que de acordo "com levantamento da Fundação Seade, a morte violenta foi a principal causa de óbito de meninos de cinco a quatorze anos entre 1999 e 2003 . Foram 283 mortes desse tipo, o que representa $17,43 \%$ do total de óbitos da faixa etária citada”.

Essas manifestações veiculadas pela imprensa evidenciam a construção de um discurso sobre a criminalidade e revelam "uma predisposição na sociedade para incorporar o discurso do caos social criado por estes setores autorizados, mesmo que a visibilidade das práticas condenáveis seja garantida apenas por aqueles que tornam públicas situações não experimentadas pela maior parte da população" (Elmir, 2002, p. 394). 


\section{A violência e a assistência: incidência e inferências}

Buscando averiguar a incidência de maus-tratos e de práticas de violência entre menores, pesquisamos os livros de Matrícula Geral de Enfermos, números 6 a 21, do Acervo da Santa Casa de Misericórdia de Porto Alegre. Entre os anos de 1890 a 1920, foram selecionadas as internações que tiveram como causa uma possível agressão à integridade física desses jovens. ${ }^{9}$

Como os dados disponíveis nesses livros são insuficientes para afirmarmos com veemência a intencionalidade da violência, esta é inferida, por isso nosso cuidado de definir tais enfermidades como provocadas por possível violência.

Em alguns casos, no entanto, o emprego de violência contra esses menores é explícito, como ocorreu com os menores C. B., 20 anos, ferido por arma branca no dorso, ou seja, atacado pelas costas; B. T. C., 16 anos, ferida a bala no tórax e J., 20 anos, que deu entrada com um "ferimento do pescoço interessando a trachéa". Todos esses três menores tiveram alta após um período de restabelecimento, porém, muitos não tiveram a mesma sorte.

Ao dividir os menores conforme suas faixas etárias, obtivemos os seguintes resultados: 6,91\% estão entre 0 e 7 anos; $13,5 \%$ têm entre 8 e 12 anos; 24,32\% estão compreendidos entre 13 e 17 anos e $48,9 \%$ possuem de 18 a 21 anos. Com base nesses dados, percebese que os jovens próximos à maioridade constituíam a maioria dos menores que buscavam a assistência médica da Santa Casa, resultante de um curioso incremento do número de atendimentos, relacionado com o avanço da faixa etária.

Devemos levar em conta também que a busca por assistência médica era o último recurso adotado pelas famílias, principalmente as de baixa renda, que procuravam curar suas crianças com práticas alternativas, como o curandeirismo e a homeopatia. Isso pode explicar, de certa forma, a presença pouco significativa de crianças no hospital. ${ }^{10}$ 
Seguindo o mesmo raciocínio, podemos supor que aqueles mais próximos à maturidade possuíam autonomia suficiente para eles próprios buscarem tratamento para seus males, impelindo-os para os tratamentos oferecidos pela medicina hospitalar.

As enfermidades que relacionamos com uma possível violência são as seguintes: ferimentos, que aparecem divididos em três categorias: a) incisos, cortantes, perfurantes ou por arma branca; b) provocados por arma de fogo; c) ferimentos em geral: ${ }^{11}$ queimaduras; traumas e fraturas; suspeitas de estupro; contusões, luxações e escoriações; esmagamentos; envenenamento e intoxicação e, finalmente, hemorragias. Destas que relacionamos, as que mais provocaram internações foram as contusões, luxações e escoriações, com 268 entradas, sendo seguidas pelos ferimentos incisos (263 casos) e traumas e fraturas (193 casos).

Tabela 1 - Causas de internações

\begin{tabular}{l|c}
\hline Etiologia & $\mathrm{N}^{\circ}$ \\
\hline Ferimentos incisos & 263 \\
\hline Ferimentos por arma de fogo & 136 \\
\hline Ferimentos em geral & 141 \\
\hline Queimaduras & 61 \\
\hline Traumas e fraturas & 193 \\
\hline Suspeita de estupro & 3 \\
\hline Contusões, luxações e escoriações & 268 \\
\hline Esmagamentos & 82 \\
\hline Envenenamento e intoxicação & 23 \\
\hline Hemorragias & 6 \\
\hline
\end{tabular}

Com menor incidência, mas nem por isso menos preocupantes, estão os envenenamentos e intoxicações ( 23 casos), as hemorragias ( 6 casos) e as suspeitas de estupro (3 casos). Destes, apenas o último não registra óbitos. 
Os registros de óbito, tendo como causa uma possível violência, dão-nos um perfil de suas vítimas. A divisão das enfermidades por classes é complementada por informações como a idade média, profissão e sexo dos jovens, buscando relacioná-los.

Os ferimentos em geral, provocados por arma de fogo e perfurantes, vitimavam, principalmente, jovens de 18, 20 e 21 anos, esmagadora maioria de rapazes. Os traumas, fraturas, contusões, luxações e escoriações levavam a óbito muitos rapazes. Nãoé possível traçar uma idade média, já que acometem várias faixas etárias. Esmagamentos e hemorragias não definem nitidamente um grupoalvo, salvo a idade dos menores falecidos por tal enfermidade: todos tinham 20 anos.

Com idades entre 16 e 18 anos, moças ligadas ao serviço doméstico eram as que mais morriam por queimaduras, intoxicação e envenenamento. Os casos de envenenamento ocorrem, em grande parte, por causa de produtos de limpeza e venenos para pragas domésticas, como a creolina, o verde Paris ${ }^{12}$, sal de cobre ${ }^{13}$ e arsênico. A utilização inadequada, e até mesmo a toxicidade dos produtos, podem ter provocado essas mortes.

Os ferimentos incisos foram a causa do maior número de mortes, considerando o total de internações, com 16 óbitos registrados. Relacionando, porém, o número de internações com o índice de mortalidade em cada categoria, as hemorragias despontam como a que mata o maior número de pacientes atendidos, com um índice de $50 \%$ (6 internações -3 óbitos).

Ao fazermos uma análise do gráfico relativo ao número de internações que decorrem da prática de violência, percebe-se a importância da categoria. Porém, dos 1.229 casos relacionados, apenas 67 foram a óbito, o que é um número surpreendente baixo, dadas as condições dos hospitais e a terapêutica rudimentar. ${ }^{14}$

É importante ressaltar que, a partir da segunda metade do século XIX, a Ciência Jurídica, a Medicina e a Psiquiatria voltaram 
seus olhos para as "aberrações sexuais", para os amores "contra a natureza", para os "maníacos" e "perversos". Interessava analisar esses fenômenos exatamente para mantê-los à margem, para melhor conservar a integridade e a saúde dos indivíduos "normais". Para os juristas, o pudor estava ligado à dignidade pessoal, ao amor próprio, à honra e aos costumes, base da sociedade. Eram, principalmente, a mulher, a família e o lar os principais atingidos pelos "ataques de impudícia", a fim de "saciar paixões lascivas". Essas atitudes anormais existiram em função da fragilidade do sexo, das más companhias, do abandono dos pais e da falta dos "sentimentos da família, da honra, do trabalho e da grandeza da pátria". O artigo 266 do Código Penal Brasileiro de 1890 iria tratar do crime de ultraje público ao pudor, manifestando-se em relação à prática de "atos de libidinagem" com menor de idade.

Tabela 2 - Causas de óbitos

\begin{tabular}{l|c}
\hline Óbitos & $\mathrm{N}^{\mathrm{o}}$ \\
\hline Ferimentos incisos & 16 \\
\hline Ferimentos por arma de fogo & 10 \\
\hline Ferimentos em geral & 1 \\
\hline Queimaduras & 12 \\
\hline Traumas e fraturas & 14 \\
\hline Contusões, luxações e escoriações & 6 \\
\hline Esmagamentos & 3 \\
\hline Envenenamento e intoxicação & 2 \\
\hline Hemorragias & 3 \\
\hline
\end{tabular}

Nas últimas décadas do século 19, considerava-se violência o ato sexual com uma pessoa menor de idade, ${ }^{15}$ mesmo que ela tivesse consentido. A "criminalização da sexualidade" visava a controlar, portanto, a sexualidade dos adolescentes para que estes não se transformassem em "pervertidos". Entre os delitos catalogados pelos 
criminólogos constavam o defloramento, o estupro, o atentado ao pudor, o rapto e o adultério. ${ }^{16}$ Em todos eles estava presente a questão sexual, sendo que outras práticas como, o sadismo, o incesto e a perda da virgindade eram também analisados pelos juristas.

O defloramento constava como crime no Código Penal Brasileiro de 1890, em seu art. 267. Para tanto, fazia-se necessária a cópula com uma mulher virgem e o rompimento do hímen, mediante consentimento obtido por sedução, engano ou fraude. Caso não houvesse cópula, o delito seria atentado ao pudor. Sem o consentimento da mulher, o crime seria estupro. ${ }^{17}$

O Código Penal de 1890, no art. 269, definiu como estupro o ato sexual com uma mulher sem o seu consentimento, ou seja, com a utilização de violência, diferindo, pois, do defloramento consentido. Tanto no defloramento, quanto no estupro, a existência de laços de sangue e parentesco, relações de dependência ou facilidade para realização do atentado ou a impossibilidade de casar-se eram consideradas circunstâncias agravantes. Entre os parentes estavam englobados pais, irmãos e cunhados; nas relações de dependência, tutor, curador, encarregado de guarda e educação ou quem tivesse alguma autoridade sobre a vítima. Tanto nas situações de crime de defloramento, quanto nas de estupro, o indivíduo viria a ser processado somente com a formalização de queixa da vítima. ${ }^{18} \mathrm{~A}$ relação sexual incestuosa não era considerada propriamente um crime, entretanto, era penalizada como defloramento ou estupro.

Também pelo mesmo Código, em seu art. 270, foi considerado crime o rapto, ou seja, retirar do lar doméstico, mulher honesta através da violência ou sedução. Caso a ele se seguisse o defloramento ou o estupro, o indivíduo seria enquadrado também nesses artigos. ${ }^{19}$

O estudo realizado por Sueann Caulfield (2001), Em defesa da honra: moralidade, modernidade e nação no Rio de Janeiro (1918-1940), constatou que as queixas de defloramento estiveram entre as mais freqüentes queixas criminais até a década de 1940, 
perdendo apenas para lesões corporais e roubo, e lideravam de longe a lista de crimes sexuais até os idos de $1970 .^{20}$

As mulheres que se apresentavam como "ofendidas" (vítimas de crime sexual) precisavam provar sua honestidade e a de sua família para serem, então, consideradas merecedoras de proteção da justiça. Mulheres honestas, por exemplo, não possuíam desejo sexual. Os homens acusados de crimes sexuais também eram julgados por sua conduta social, por aquilo que eles eram ou pareciam ser, e não somente por serem ou não os autores do crime pelo qual eram acusados. Homens de "bom caráter", trabalhadores, tinham mais chance de serem absolvidos.

[...] ao ser julgado um crime de defloramento, estupro ou atentado ao pudor, resultante da quebra de uma norma jurídica sexual, emergiam os valores sociais mais amplos da sociedade, pois eram também na quebra de outras normas morais e sociais que se determinava a absolvição e condenação do réu. Ou seja, a conduta total do indivíduo é que iria, ou não, redimi-lo de um crime; não estava em pauta apenas o que havia sido feito, mas aquilo que o acusado e a ofendida eram, poderiam ser ou seriam. (Esteves, 1989, p.41)

Como afirma a já citada Marta de Abreu Esteves (1989, 41), "o aprofundamento das correlações entre honestidade, moral e bom trabalhador, no meio jurídico, formavam um triângulo referencial riquíssimo na sociedade que se desejava formar".

$\mathrm{O}$ fato de as mulheres serem vistas por médicos e juristas como esposas e mães, e o casamento (e as relações sexuais dentro deste) como base da família e da pátria (questões de higiene e moral) deixa claro que meninas defloradas, estupradas ou alvo de atentado ao pudor eram "situações desviantes" e que representavam uma "ameaça à ordem sexual". ${ }^{21}$ Assim, "aquela que não preenchesse os requisitos estipulados pela natureza, inscrevia-se no campo sombrio da anormalidade, do pecado e do crime", pois “não amamentar e não ser esposa e mãe significava desobedecer à ordem natural das coisas, ao mesmo tempo que se punha em risco o futuro da nação" (Rago, 1985, p. 79). 
Na concepção positivista, a mulher constituía-se na "reserva moral da sociedade, freio dos maus instintos e suavizadora de conflitos", e que a "permanência no lar [...] era uma garantia de manutenção da ordem social. [...] era um fator de controle dos conflitos sociais, que poderiam ser contornados e mesmo impedidos através da ação moralizadora da personagem feminina" (Pesavento, 1990, p. 72-73).

Em razão dessa concepção de mulher como "alma da família", estabeleceu-se uma rígida moral que entendia o casamento como caminho natural, "mas antes de chegar lá, era preciso vigiar as jovens e preservar a virgindade das moças, coibindo namoros" (Pesavento, 1990, p. 74).

Eram freqüentes, nos jornais das duas últimas décadas do século 19, notícias de meninas que eram seduzidas e arrastadas aos prostíbulos e de crianças (meninos e meninas) que esmolavam e perambulavam pelas ruas, atraídas por toda sorte de vícios. A responsabilidade por esta situação de desamparo da infância era imputada às mães que falhavam em sua tarefa de educadoras, mas também, à ausência de políticas públicas orientadas para a juventude.

Os dados levantados junto ao Arquivo Histórico e ao Arquivo Público do Rio Grande do Sul apontam para um número significativo de registros que referem a violência cometida contra meninas, o que se observou tanto nos códices da polícia e nos processos-crime, quanto nas solicitações de exames de corpo de delito por atentado ao pudor encontrados na documentação analisada. ${ }^{22}$

Ao contrário dos registros da Santa Casa, os processos-crime do Cartório do Júri nos dão informações mais específicas quanto às razões que motivaram a violência contra os menores. A menor A. S., de 15 anos, teve a suspeita de estupro confirmada com um exame médico que verificava o desenvolvimento de seu corpo como um todo e, mais especificamente, as genitais, observando a existência ou não de pêlos, a aparência dos pequenos e grandes lábios e clitóris, a presença do hímen e a dilatação da vagina. ${ }^{23}$ Com base nesse exame, os peritos respondiam aos seguintes quesitos: 
Primeiro quesito: se houve deffloramento; Segundo - sé é recente ou antigo. Terceiro quesito - qual o meio empregado; Quarto quesito - se houve copula carnal; Quinto quesito - se houve emprego de hypnotismo, de substancia anesthesica ou narcotica para consecução do crime." Constataram, então que: "[...] ao primeiro quesito - sim, houve deffloramento; ao segundo - não é recente; ao terceiro introdução de membro viril; ao quarto - sim; ao quinto - não. (APRGS Processo-crime n.1, 1897).

Com base nesses dados, o estupro da menor foi confirmado, sendo que o autor foi o próprio irmão, com quem vivia após a morte de seus pais. Este é ainda acusado de ter também estuprado a cunhada, que tinha 13 anos na época do ocorrido. Pela mesma situação passou J., de 10 anos, tendo sido vítima de estupro recente. $\mathrm{O}$ autor foi um soldado da Brigada Militar, deixando-a "em deplorável estado" (AHRGS, Códices da Polícia - Livro 4, 1896, p. 74).

Os exames médicos eram precariamente realizados na primeira década do século, evidenciando imperícia e determinando confusão a respeito do defloramento e da integridade do hímen, mesmo porque o próprio Código Penal em vigor à época previa a associação entre defloramento e ruptura de hímen e alguns juristas defendiam a existência de uma aproximação lógica entre dores físicas, sangue, virgindade e comportamento honesto (Ver Esteves, 1989, p. 60-63).

Martha de Abreu Esteves, em seu livro Meninas perdidas: os populares e o cotidiano do amor no Rio de Janeiro da Belle Èpoque (1989), analisa como o aparelho jurídico, através do julgamento de crimes sexuais, exerceu, ampliou seu controle e influenciou o comportamento ("nova política sexual") do trabalhador carioca na primeira década do século XX.

Nos processos-crime que analisamos pudemos constatar o julgamento moral realizado por médicos e juristas do Rio Grande do Sul:

Em consequencia passaram os peritos a fazer os exames e investigações ordenadas as quaes declararam o seguinte: a paciente apresente desenvolvimento extraordinário para a idade que diz ter 
(doze annos incompletos), responde, com clareza e naturalidade as perguntas que lhe são dirigidas. [...] e que portanto, respondem: ao primeiro quesito, sim, existem signaes evidentes de que a paciente tem entretido relações sexuaes: firmamos este juízo deante do facto de apresentar-se o hymem com pequena ruptura, como foi descripta, assim como no estado de frouxidão do mesmo, deixando penetrar sem difficuldade o dedo medio; segundo, as relações já devem ser entretidas desde algum tempo porquanto a cicatrização da ruptura é perfeita; terceiro, sim, e deste modo pode ser explicado o extraordinário desenvolvimento das partes sexuaes numa menina de doze annos [...]. (AHRG S, Códice da Polícia, 1896, p. 51).

Já o menor A. B. sofreu lesão corporal por parte do açougueiro O. M., para quem trabalhava. $\mathrm{O}$ exame de corpo de delito procurava responder as seguintes questões:

[...] primeiro, si ha ferimento ou offensa physsica; segundo, qual o meio que ocasionou; terceiro, si foi ocasionado por veneno, substancias anesthesicas, incêndio, asphyxia ou innundação: resposta especifica; quarto, si por sua natureza ou [...] pode ser causa efficiente da morte; quinto, si a constituição ou estado morbido anterior do offendido concorreram para tornal-o irremediavelmente mortal; sexto, si das condições personalíssimas do offendido pode resultar a morte; setimo, si resultou ou pode resultar de algum órgão ou membro: resposta especificada; oitavo, si resultou ou pode resultar em enfermidade incurável e que prive para sempre o offendido de poder exercer seu trabalho: resposta especificada; nono, si produsiu incommodo de saúde que inhabilite e o paciente de poder exercer o seu trabalho por mais de trinta dias. Em consequiência pasaram os peritos a fazer os exames e investigações ordenadas, e as que julgaram necessárias, concluidas as quaes, declararam o seguinte: apresenta o paciente duas escoriações na face, região mollar e masseterina esquerda; e que, portanto, respondem: ao primeiro quesito sim; ao segundo instrumento contundente, ao terceiro, quarto, quinto, sexto, setimo, oitavo, nono, não. (APRGS, Processo-crime n. 33, 1896).

O autor da lesão do menor afirmou que apenas dera um puxão de orelha em A. B. e que a própria mãe o havia autorizado a castigar a criança se seu comportamento lhe desagradasse. Segundo o registro nos códices da polícia, a mãe solicitou ao açougueiro que mantivesse o emprego do filho após o ocorrido (AHRGS, Códices da Polícia Livro 3, p. 27). O mesmo exame foi procedido em C. J. M., 16 anos, 
agredido com uma pá ao ajudar um colega em seu serviço, e com $\mathrm{N}$. S., 10 anos, ferido nas nádegas com uma faca por fazer travessuras num estabelecimento comercial.

Entre os casos que localizamos nos processos-crime do Cartório do Júri, destacamos um que se refere à prática de envenenamento. Vítima de envenenamento por formicida, M. C., 14 anos, faleceu. O veneno, segundo o registro, fora posto em seu café por uma exserviçal da casa que a julgava responsável por sua demissão.

As informações detalhadas que encontramos nos códices da polícia e nos processos-crime nos permitem visualizar com mais nitidez os crimes cometidos contra esses jovens. No entanto, ao compararmos esses dados com os registros da Santa Casa, nenhum coincidiu, ou seja, os menores mencionados acima não foram encaminhados a esse hospital, o que nos distancia ainda mais de nosso objetivo de perseguir e cotejar os dados levantados nos acervos documentais.

Com base nesses relatos, percebemos que, apesar da mudança conceitual de infância e dos esforços de intelectuais, médicos e políticos em conduzir os jovens a um "futuro promissor", isto parece não ter alcançado a compreensão de parte significativa de setores da sociedade porto-alegrense no período analisado, na medida em que os fenômenos de ordem estrutural determinantes dos "comportamentos desviantes" permaneceram intocados. A inoperância e a ineficácia dos debates e das políticas públicas encaminhadas nesse período apontam para a existência de outras motivações para a delinquiência entre crianças e adolescentes que não as exclusivamente relacionadas com a formação e a educação familiar e que denotam uma visão conservadora da situação social.

\section{A transformação desejada: os menores na Casa de Correção}

Para muitos intelectuais, jornalistas e políticos do final do século XIX, a civilização e o progresso estavam associados à imposição de 
um determinado padrão de ordem e de comportamento moralizado no espaço público. Em Porto Alegre, como em outras cidades do País, o crime, a desordem e o suposto comportamento desregrado das classes populares eram vistos como marcas do atraso que se desejava superar na recém-instalada República.

Em seu livro $O$ cotidiano da República, Sandra Jatahy Pesavento (1990) destaca a preocupação da sociedade gaúcha com o destino das crianças pobres, muitas vezes abandonadas nas ruas ou deixadas na "roda dos expostos" da Santa Casa. Eram freqüentes, segundo Pesavento, as notícias de crianças desaparecidas, mortas, seduzidas, pedindo esmolas e perambulando, atraídas pelo jogo e pela bebida. Essas crianças, consideradas como uma ofensa à moral $\mathrm{e}$ aos bons costumes, sofriam toda sorte de violências por parte da polícia administrativa encarregada de garantir uma "sociedade tranqüila".

O estudo de Cláudia Mauch (2004) refere também a preocupação em relação ao "grande número de raparigas entre treze e dezesseis anos que, precocemente prostituídas, viviam percorrendo as ruas da cidade", do que resultou a proposta da fundação de instituições de proteção às meninas pobres e prevenção à prostituição ao encargo das congregações religiosas da capital. ${ }^{24}$

Não encontramos, no que se refere ao período em questão, referências a instituições como o Instituto de Proteção e Amparo à Infância ou o Instituto Disciplinar de São Paulo no Rio Grande do Sul. O destino dos menores infratores gaúchos era a Casa de Correção de Porto Alegre, construída à beira do Guaíba entre 1852 e 1855. A população carcerária, ao longo do século XIX,

[...] foi crescendo progressivamente, pois recebia não só os criminosos da capital como de todo o interior do Rio Grande. Em 1888, chegava à cifra de 392 pessoas, um excesso de população que causaria preocupação às autoridades. A superlotação ameaçava o estado sanitário do ambiente carcerário, que ficava assim sujeito à proliferação de doenças que poderiam se espalhar pela cidade. $\mathrm{O}$ fato de ser a principal Cadeia da Província levava, por si só, a esta superlotação, pois o presídio da capital era inclusive o local onde o 
preso vindo do interior aguardava a solução final de seu caso. (Pesavento, 2003)

Como é possível observar, as condições da Casa de Correção eram precárias e esta situação já havia sido constatada em 1885 quando uma comissão formada pelo cronista Achylles Porto Alegre, pelo futuro presidente do Estado Júlio de Castilhos, pelos jornalistas Felicíssimo Manoel de Azevedo e João Câncio Gomes e pelo médico e político Ramiro Barcellos visitou a Cadeia. Frente à necessidade de melhor gerir o espaço urbano, a comissão visitou, além da Casa de Correção, outros dois espaços de confinamento dos excluído da cidade: o Hospício São Pedro e Santa Casa de Misericórdia de Porto Alegre. Apontando a precariedade de condições da Cadeia, com acomodações previstas para 150 pessoas e ocupadas por 450 , a comissão descreveu o ambiente "com cores negras":

[...] acrescente-se a este quadro as paredes negras, as goteiras, o abafamento, a promiscuidade, a confusão de espaços, com materiais fecais em tinas vizinhas àquelas para a lavagem de roupa: tudo isto denunciava erros de administração, falta de verbas e má condição de vida dos presos. As palavras usadas para qualificar o ambiente e seus ocupantes são significativas. A cadeia é 'antro', é 'inquisitorial prisão', com espaços onde se respiram 'os mais nocivos miasmas', sem renovação de ar; os presos são, por sua vez, designados como 'infelizes', 'miseráveis' e 'desgraçados'. (Pesavento, 2003)

Os ideais de "modernização" e "civilização", objetivos das elites brasileiras no início do período republicano, também se projetavam sobre o sistema carcerário. Segundo Pesavento, o Relatório da Secretaria dos Negócios do Interior e Exterior apontava, em 1895, a necessidade de reformas inadiáveis no sistema carcerário, "até que o Estado pudesse criar um estudo segundo as conclusões da criminologia contemporânea" (Pesavento, 2003). Dentre as transformações preconizadas, a autora destaca a importância da construção de oficinas, a realização de reformas na enfermaria, a adoção de uma ambulância, o uso de filtro para água potável, a aquisição de cubos para matérias fecais e a colocação de vidros nas janelas. 
Através do álbum photographico, organizado pelo Dr. Sebastião Leão, diretor da Officina de Antrophologia Criminal, fundada em 1895, pudemos calcular a porcentagem aproximada dos menores de idade registrados na Casa de Correção de Porto Alegre em 1897. ${ }^{25}$ O total de detentos registrados no Álbum era de 101, dos quais 13 tinham 21 anos ou menos $(12,87) .{ }^{26}$ Dos 13 casos envolvendo menores de idade, 11 haviam sido presos por homicídio (84,6\%), como os casos de T. V. que, em 1895, aos 17 anos, assaltou uma casa e, encontrando duas crianças, degolou-as e lançou os cadáveres num poço; e J. S. $\mathrm{N}$. que, aos 15 anos, assassinou um padre. Os outros dois menores registrados no álbum foram classificados como "gatunos".

No que se refere às penas atribuídas aos menores infratores encontramos, nos processos-crime pesquisados junto ao Arquivo Público do Rio Grande do Sul, casos como o de A. P. de O., 16 anos (Processo-crime, n. 15, 1896), acusado de roubo e cuja condenação correspondia ao artigo 356 e ao artigo 42 do Código Penal, ou seja, por "subtrahir, para si ou para outrem, cousa alheia movel, fazendo violência à pessoa ou empregando força contra a cousa" (Brasil, Código Penal,1909) foi condenado à prisão celular por dois a oito anos (artigo 356). O artigo 42 significava algum atenuante na pena. Já A. D. assassinou, aos 18 anos, um homem em São Sebastião do Caí e foi condenado a 30 anos de prisão celular (APRGS, Processocrime n. 39, 1897).

Outra fonte documental utilizada para o levantamento de menores de idade detidos na Casa de Correção de Porto Alegre foi seu livro de óbitos. Os dados pesquisados no Arquivo Histórico do Rio Grande do Sul até o presente momento correspondem aos anos de 1890/91 (AHRGS, Livro de Óbitos). Dos 28 óbitos registrados nesse período, 4 se referem a óbitos de menores de idade, compreendendo $14,28 \%$.

Quanto ao tratamento recebido pelos menores na Casa de Correção, sabemos que estes presos recebiam alguns tratamentos diferenciados. ${ }^{27} \mathrm{O}$ Regulamento Especial da cadeia civil de Porto 
Alegre (27 de fevereiro de 1857) determinava, em sua Seção V Da classificação e subdivisão das prisões na cadeia, Artigo 35 e parágrafos 1, 2, 6 e 7, que os menores de idade seriam classificados de forma diferente dos outros presos da cadeia. O parágrafo $1^{\circ}$, por exemplo, estabelecia que "as prisões números 1, 2, 3, 6, 10, 11 e 19, são destinadas aos que têm sido condenados a 12 anos de galés, prisão, ou pena maior, excetuando-se unicamente os menores de 21 anos (não condenados a galés ou prisão perpétua) os quais serão conservados nas prisões números 9, 12 e 18” (apud Pesavento, 2003).

Já o Regulamento Provisório da Casa de Correção (Ato no 24, de 29 de fevereiro de 1896) estabelece, no artigo terceiro do Título Preliminar - Da Casa de Correção - que "a separação entre condenados e detidos será absoluta. As mulheres e menores serão também recolhidos a alojamento separados" (apud Pesavento, 2003). Quanto às atividades desenvolvidas durante a detenção, esse mesmo Regulamento determinava, no Título IV - Custeamento e Produtos dos Trabalhos - Artigo 104 e 105, que "para os serviços de cozinha do estabelecimento, lavanderias, enfermarias, limpeza e obras da casa serão escolhidos de preferência os condenados até dois anos de prisão, considerando-se o Estado pago de seu sustento, e quites os condenados com as custas judiciais, à vista dos serviços que prestarem" (Art. 104) mas "os menores de vinte e um anos, embora condenados até dois anos, irão sempre para as oficinas aprender ofício" (Art. 105). O Regulamento da Casa de Correção (Decreto $n^{\circ}$ 2.012, de 22 de agosto de 1913) manteve as determinações do regulamento provisório de 1896 no que se referia aos menores de idade (apud Pesavento, 2003).

De acordo com Alvim \& Valladares (1988, p. 9-10), somente no período pós-Segunda Guerra Mundial é que o aspecto institucional da questão do menor receberá uma maior atenção de parte do Estado, traduzida em políticas sociais orientadas para a criação de espaços de sociabilidade específicos para os delinqüientes. As taxas de crescimento da população compreendida na faixa etária de zero a dezenove anos e a preocupação com a garantia da propriedade dos 
cidadãos honestos explicam as propostas de criação de educandários para menores abandonados, voltados para sua (re)educação, formuladas no período de 1950 a 1960 (Ver Elmir, 2002, p. 362-363).

\section{Considerações finais}

De acordo com o Guia de atenção frente aos maus-tratos na infância e adolescência, de 2001, editado pela Sociedade Brasileira de Pediatria, as definições para violência contra a criança e o adolescente variam de acordo com a visão cultural e histórica sobre a criança e seus cuidados, com os direitos e o cumprimento de regras sociais relacionados a ela e com os modelos explicativos do uso da violência.

A violência é usualmente entendida como ação impetrada através da força, que cause danos físicos, morais, emocionais ou espirituais a alguém. Os dados reais sobre os maus-tratos contra crianças e adolescentes são muito imprecisos, uma vez que a grande maioria dos casos não implica a busca de atendimento médico para as vítimas. Os dados existentes baseiam-se em denúncias, ou em registros de atendimentos por lesões traumáticas em hospitais e clínicas. A falta de informações objetivas nos registros de internação hospitalar impede, no entanto, uma interpretação rigorosa, especialmente em relação aos registros de esmagamentos, contusões, escoriações, luxações, queimaduras, traumas, fraturas e hemorragias.

É oportuno lembrar que, no final do século XX, seguia-se acreditando que o trabalho infantil - para as camadas populares era "a melhor escola". ${ }^{28}$ Pequenos corpos que se dobravam à violência e às humilhações intrínsecas à exploração de sua força de trabalho, tornando-se alvos fáceis para sua fragilização emocional, mutilações físicas e maioridade precoce.

Grande parte dos casos que levantamos nos registros de internação na Santa Casa refere-se a crianças e adolescentes que atuavam como carpinteiros, pedreiros, padeiros, alfaiates, chapeleiros, cozinheiros, carroceiros, operários, militares, agricultores e 
empregados domésticos, o que nos leva a crer na possibilidade de os ferimentos estarem vinculados ao trabalho que exerciam.

Com relação aos ferimentos provocados por arma de fogo, uma questão é extremamente curiosa: como tantas vítimas sobrevivem e recebem alta em um tempo relativamente tão curto? Considerando a gravidade de um ferimento desse tipo, que desafia os procedimentos médicos até hoje, como tal fato é possível em uma época em que a cirurgia era rudimentar, o ambiente não oferecia as melhores condições de higiene e os medicamentos não tinham sua eficácia química comprovada? Tiros dados na cabeça sempre eram considerados irreversíveis, não raramente ocasionando mortes ou graves seqüelas. Mas o caso de R. L., de 19 anos, cuja descrição da enfermidade é "tiro de pistola embaixo do ouvido direito", permanecendo menos de um mês internado e saindo do hospital curado, contraria essa idéia.

Internações de menores, como a de M. J. R., de 9 anos, tratado em decorrência de queimaduras (AHSCMPA, Processo $n^{\circ}$ 557, 1888 - 1892), ou então a de N. da S. D., de 8 anos, atingido por uma faca ao fazer "uma compra no estabelecimento commercial de [A. P.]" (APRGS, Processo-Crime n. 26, 1897) ou, ainda, a de L. E. S., de 7 anos, vítima de violência sexual, apontam para a prática recorrente de maus-tratos a menores e nos instigam a desvendar a infância infratora e alvo de violência no Rio Grande do Sul.

Considerando que nos propusemos a, também, identificar e analisar o encaminhamento dado pelo Estado às crianças e adolescentes infratores, praticantes de violência contra outros menores ou adultos - e que envolviam desde incestos e estupros, até assaltos seguidos de morte -, pretendemos, na continuidade, aprofundar a abordagem quanto à definição de políticas públicas relativas à infância infratora e abandonada, analisando os institutos disciplinares, ${ }^{29}$ especialmente, a Casa de Correção de Porto Alegre, em sua função de punição e recuperação social de delinqüientes.

A constatação - através do levantamento documental - de práticas como o incesto, o defloramento e o rapto de menores, e a incidência de registros de entrada na Santa Casa que atestam maus 
tratos e descaso familial, nos remete à atualidade e à pertinência de campanhas de conscientização em relação à difusão (permanência) dos problemas estruturais denunciados por higienistas, médicos, intelectuais e políticos da virada do século XIX para o século XX.

Esta investigação apresenta, portanto, significativa relevância social, na medida em que se associa ao esforço que a sociedade vem fazendo para a erradicação da violência contra a infância e para a conscientização em relação as suas causas, efeitos e estratégias de reversão. A mobilização, não exclusivamente, de intelectuais, mas de vários segmentos da sociedade, para a compreensão das estratégias de manipulação político-ideológica da infância, em vários momentos da história brasileira, pode repercutir para o resgate de sua real importância e para a ressignificação da infância.

\section{Notas}

1 Consideramos como "violência" a ação física voluntária de indivíduos sobre outros, causando dor, o que permite a construção de indicadores mais objetivos para sua quantificação. Mesmo definindo "violência" como um fenômeno relacionado com o uso da força física, esta ainda pode ser utilizada em graus bastante diversos, desde as brigas de rua sem o uso de armas, até o homicídio. Reconhecemos, em razão disso, que este é um conceito limitado de violência, já que ficamos - neste estudo - restritos à violência interpessoal passível de criminalização.

2 Deve-se ressaltar que "a formulação de políticas públicas de contenção da violência no início do século XX tem sido extensamente estudada, sendo considerada uma das principais matrizes de orientação do novo Estado republicano. Para conter a pobreza urbana, este Estado teria optado por uma política de repressão constante [...]. As ações públicas indicam uma percepção da existência de um grau significativo de violência na sociedade" (Bretas, 2002, p. 15).

3 O importante era, exatamente, abrir ao máximo possível o público-alvo das instituições preventivo-correcionais, garantindo sua formação como "trabalhadores fortes e ordeiros" através do ensino profissional. Este projeto social foi inaugurado com o Código Penal da República, de 1890, e marca a primeira grande fase de atuação do Estado frente aos menores infratores para que se tornassem cidadãos "úteis a si e à sociedade". 
Cabe, no entanto, observar que a análise da trajetória cumprida pelas crianças e adolescentes em direção à criminalidade pode ser feita em duas situações: "em primeiro lugar, aquelas que implicam prioritariamente o abandono material (menores pobres); depois, aquelas nas quais o abandono moral é o móvel primeiro na construção de um sujeito transgressor" (Elmir, 2002, p. 361).

4 A Santa Casa era uma referência no Estado do Rio Grande do Sul por prestar atendimento gratuito àqueles que não tinham como pagar um médico particular. Era predominante a idéia de que hospital era lugar para morrer, o que fazia com que muitos fugissem ou se recusassem a entrar no hospital. Casos como o de A. R. S., de 21 anos, que não teve sua doença diagnosticada por recusar-se a receber atendimento. Por outro lado, os prontuários de que dispomos dão conta apenas do motivo da internação, não havendo qualquer registro sobre as causas das lesões ou ferimentos, o que dificulta uma possível distinção entre acidente e maus tratos.

5 Cabe esclarecer que, para além de um levantamento meramente quantitativo dos delitos cometidos e registrados, interessa-nos avaliar qualitativamente esses delitos, razão pela qual se tornam tão significativas as informações relativas às motivações e aos procedimentos adotados pelos infratores. Assim, consideramos a existência de uma gradação no caráter e nas condutas delituosas dessas crianças e desses adolescentes.

6 A etiologia e os fatores determinantes do abuso sexual diferem dos outros tipos de maus-tratos, envolvendo questões culturais, de dependência social, econômica e afetiva entre os membros de uma família, o que dificulta a notificação da prática.

7 Pelo uso de adjetivos como "pequenos delinqüentes, desajustados, pequenos monstros" imputados aos menores, constata-se como foi construída a imagem do infrator de alta periculosidade, diante do qual a sociedade aparece como impotente, passando a cobrar do Estado a criação de estabelecimentos de reeducação para interná-los.

8 Um documento do Unicef amplia a visão em relação às ameaças que pairam sobre os jovens em nosso país: $45 \%$ das crianças e adolescentes do Brasil vivem abaixo da linha de pobreza, o que em números absolutos abrange 27,4 milhões que estão perdendo a infância. Estes dados mostram-se assustadores e revelam o fracasso da sociedade humana na proteção do seu futuro, apesar de algumas iniciativas orientadas para o atendimento de crianças desassistidas e com fome. 
9 Atualmente os maus-tratos obedecem à seguinte classificação: maustratos físicos decorrem do "uso da força física de forma intencional, não acidental, praticada por pais, responsáveis, familiares ou pessoas próximas da criança ou adolescente, com o objetivo de ferir, danificar ou destruir esta criança ou adolescente, deixando ou não marcas evidentes" (Soc. Bras. de Pediatria, 2001, p. 11). Os dados reais sobre os maus-tratos contra crianças e adolescentes são muito imprecisos, porque dependem tanto da busca de atendimento médico, quanto de denúncia sobre a violência intrafamiliar que raramente ocorrem. Admite-se que, para cada caso notificado às autoridades competentes, existam outros vinte que não foram informados, impedindo que se avalie a exata magnitude do problema.

10 Segundo os Relatórios do Dr. Protásio Alves, o maior número de óbitos, em decorrência da falta de assistência médica, pertence a crianças. A falta de informação da causa mortis nos óbitos - declarados sem assistência médica - podem, no entanto, ter encoberto vários casos de maus-tratos que deveriam ter sido comunicados à Polícia (Rio Grande do Sul, Secretaria do Interior e Exterior, 1893, p. 12-12).

11 Considerando o número de militares envolvidos no levantamento feito, em especial, em internações decorrentes de ferimentos perfurantes e de arma de fogo, cabe referir que "embora não mencionada pelos jornais, a proximidade entre várias das zonas de desordem e quartéis oportunizava o contato e o conflito cotidiano entre os supostos mantenedores da ordem e os desordeiros. Os agentes da Guarda Municipal e depois da Polícia Administrativa, embora em menor número, não estavam de todo ausentes desses conflitos. Em muitos casos, por ter sido a polícia municipal destacada para restabelecer a ordem numa espelunca, acabava por se envolver na briga" (Mauch, 2004, p. 91).

$12 \mathrm{O}$ verde Paris (acetoarsenito de cobre) provoca irritação no nariz, olhos, pele e garganta, podendo ser mortal se ingerido ou inalado.

$13 \mathrm{O}$ indivíduo intoxicado pelo sal de cobre (acetato de cobre) sofre de irritação no nariz, pele e garganta, podendo causar queimaduras nos olhos. Se inalado, causará tosse ou dificuldade respiratória. Se ingerido, provoca náusea, vômito ou perda de consciência.

14 Beatriz Teixeira Weber, em seu livro As artes de curar, refere como os doentes eram tratados: todos reclusos na mesma enfermaria, independente do tipo de doença que apresentassem. Além disso, no prédio da Santa Casa faltavam leitos, equipamentos, luz e ventilação. O serviço de enfermagem era insuficiente e negligente, sendo que, em 
grande medida, as ordens médicas eram contrariadas, denotando menosprezo pelo conhecimento científico (Weber, 1999, p. 147, 151-152). Não havia desinfecção, nem esterilização dos instrumentos e roupas de cama, sendo que exames laboratoriais eram feitos no mesmo ambiente em que doentes graves se encontravam instalados (Weber, 1999, p. 16).

15 De acordo com Adriana de Resende Vianna (1999, p. 25-27), era considerado menor o indivíduo situado nos limites etários da maioridade, o que implicava uma absoluta ausência de gestão sobre seu destino e, ainda, uma total desvalorização de qualquer argumento por ele utilizado.

16 No século XIX, o corpo feminino era considerado de responsabilidade e de direito de seus genitores. Em casos de estupro, não era o corpo estuprado que era considerado a principal vítima e sim os seus genitores ou responsáveis. No Código Penal de 1890, as ofensas sexuais eram consideradas "crime contra a segurança da honra e honestidade das famílias".

17 O Código Penal de 1890 definiu como estupro o ato sexual com uma mulher sem o seu consentimento, mediante utilização de violência. De acordo com Mazzieiro (1998, p. 31), a mulher casada não podia dar queixas do marido por estupro, pois o uso da força em face de resistências ao ato sexual não se constituía em crime, mas em exercício de direito marital.

18 De acordo com Martha de Abreu Esteves (1989, p. 61), “as mulheres que desejavam ser protegidas pela Justiça, além de atribuírem em seus relatos toda a ação ao homem, deviam dar muita ênfase à dor e ao sangue", pois eram os "emblemas da virgindade". A comprovação da perda da virgindade era elemento característico do delito e para prová-la era necessário o exame de corpo de delito.

19 Segundo a análise de Esteves (1989, p. 119), os juristas defendiam que "a honra era sinônimo de virgindade sexual e ideal de casamento", vinculando-a a "determinadas atitudes consideradas morais", ou seja, "para a coexistência dos valores de virgindade e casamento era necessária a prática de determinados comportamentos".

20 Embora estejamos interessados em analisar os dados referentes à violência cometida contra menores num período anterior ao que foi alvo da investigação de Caulfield, consideramos significativas as suas conclusões, a partir das quais estabelecemos aproximações.

21 No início do século XIX, a veneração da castidade feminina era a responsável pelo alto número de assassinatos relacionados com a honra sexual e pela enxurrada de queixas de defloramento que assolavam as delegacias de polícia. Uma nova geração de juristas iria rever os conceitos 
de honra e virgindade, na década de 20, dirigindo seu foco de preocupação para a proteção dos chamados menores, em vez de centrarse na preocupação com a virtude feminina.

22 Entende-se por abuso sexual todo ato ou jogo sexual, relação heterossexual ou homossexual cujo agressor está em estágio de desenvolvimento psicossexual mais adiantado que a criança ou o adolescente. Essas práticas eróticas e sexuais são impostas à criança ou ao adolescente pela violência física, por ameaças ou pela indução de sua vontade.

23 A imprecisão na diferenciação entre defloramento e atentado ao pudor nos exames realizados e informados pelo Gabinete Médico Legal constantes dos Relatórios da Secretaria do Interior e do Exterior do Rio Grande do Sul, decorre da precariedade com que esses eram realizados.

24 A percepção da cidade de Porto Alegre como lugar de "decadência moral" foi também abordada por Anderson Vargas (1992), que a associa ao "pensamento reacionário europeu" da segunda metade do século $\mathrm{XX}$.

25 O álbum foi divulgado no e-book Visões do cárcere, de Sandra Jatahy Pesavento. O álbum encontra-se no Museu de Polícia Civil Major Febeliano Faibes da Costa em Porto Alegre.

26 O álbum organizado pelo Dr. Sebastião Leão não registrava todos os detentos da Casa de Correção em 1897.

27 Ver legislação transcrita e divulgada no CD-Rom do $1^{\circ}$ Seminário de Pesquisa do Arquivo Histórico do Rio Grande do Sul, 2001.

28 Marilena Chauí (1983, p.57), chama a atenção para o preconceito de que são alvo as classes populares, pois "carregam os estigmas da suspeita da culpa e das incriminações permanentes", sendo consideradas "potencialmente criminosas".

29 Foucault 1977, ao estudar as instituições asilares, observou que estão orientadas a fazer com que os internados reaprendam valores anteriormente perdidos, para, posteriormente, retornar ao convívio social.

Abstract: From aggression to assistance, from infraction to correction: youngsters and urban violence

The article deals with urban violence, mainly against children and youngsters in Rio Grande do Sul, between 1890 and 1920, highlighting the medical assistance, which follows violence, and public policies 
on health care and social rescue for young infractors. The documental sources, although rarely offer explicit indications about the motives of infractions and consequent hospitalizations, allow inferences through the relationship established between the inflicted wounds and the means to cause them. Regarding mistreat and indecent sexual behavior, the findings are based on denouncements, on police reports and on the incidence of accomplished corpus delicti exams.

Key-words: urban violence, young infractors, public policies, Rio Grande do Sul State.

\section{Fontes documentais}

ARQUIVO HISTÓRICO DO RIO GRANDE DO SUL (AHRGS). Códices da Polícia. Livro 04, 1896, p. 51. Defloramento da menor C. S. . Códices da Polícia. Livro 3, 1895, p. 27. Lesão Corporal em A. B. . Livro de Óbitos da Casa de Correção de Porto Alegre. (J - 068).

ARQUIVOHISTÓRICODASANTACASADE MISERICÓRDIADE PORTO ALEGRE (AHSCMPA). Livro de Matrícula Geral de Enfermos (n. 6 a n. 21). Período: 1890 - 1920.

ARQUIVO PÚBLICO DO RIO GRANDE DO SUL (APRGS). Processo-crime - Cartório (do) Júri. Maço 1, n. do processo 3, Estante 29, 1885. Caso de pederastia envolvendo o menor L. E. S.

. Processo-crime - Cartório (do) Júri, Maço 1, n. do processo 15, estante 29, 1896. Caso de A. P. de O.

. Processo-crime - Cartório (do) Júri. Maço 1, n. do processo 33, 1896. Caso de A. B.

. Processo-crime - Cartório (do) Júri. Maço 1, n. do processo 1, Estante 29, 1897. Caso de estupro da menor A. S.

. Processo-crime - Cartório (do) Júri. Maço 2, n. do processo 26, Estante 29, 1897. Caso de lesões corporais e tentativa de homicídio do menor N. da S. D.

Processo-crime - Cartório (do) Júri. Maço 1, n. do processo 39, 1897. Caso de A. D.

RIO GRANDE DO SUL. SECRETARIA DO INTERIOR E EXTERIOR. Relatório-SIE 3-001, 1893. 


\section{Referências bibliográficas}

ALVIM, Maria Rosilene B.; VALLADARES, Lícia do Prado. Infância e sociedade no Brasil: uma análise da literatura. BIB, Rio de Janeiro, n. 26, p. 3-37, 1988.

BRASIL. Código Penal da República dos Estados Unidos do Brasil (1890). 5. ed. Rio de Janeiro: Livraria Garnier, 1909.

BRETAS, Marcos Luiz. As empadas do confeiteiro imaginário. Acervo, Rio de Janeiro, v. 15, n. 1, p. 7-22, jan./jun. 2002.

CAULFIELD, Sueann. Em defesa da honra: moralidade, modernidade e nação no Rio de Janeiro (1918-1940). Campinas: Unicamp, Cecult, 2001.

DEL PRIORE, Mary. Criança e crianças: história e memória em quinhentos anos de Brasil. Conferência proferida no Seminário de Tropicologia: Brasil: 500 anos de uma civilização tropical, 1999, Recife. Disponível em: <www.tropicologia.org.br/conferencia>. Acesso em: 1 dez. 2004.

ELMIR, Cláudio Pereira. A enunciação do limite: os menores e o caminho para a criminalidade. Justiça e História. v. 2, n. 3, p. 359-398, 2002.

ESTEVES, Martha de Abreu. Meninas perdidas: os populares e o cotidiano do amor no Rio de Janeiro da Belle Époque. Rio de Janeiro: Paz e Terra, 1989.

FOUCAULT, Michel. Vigiar e punir. Rio de Janeiro: Vozes, 1977.

MARCÍLIO, Maria Luiza. O menor infrator e os direitos da criança no século XX. In: DIREITOS Humanos em Dissertações e Teses da USP (1934 - 1999). Comissão de Patrimônio Cultural. São Paulo: EDUSP, Imprensa Oficial, 2000. p. 41.

MARIANI, Júlio. O desafio da violência. Zero Hora, Porto Alegre, 2 dez. 2004, Editoriais, p. 20.

MAUCH, Cláudia. Ordem pública e moralidade: imprensa e policiamento urbano em Porto Alegre na década de 1890. Santa Cruz do Sul: EDUNISC, ANPUH-RS, 2004.

MAZZIEIRO, João Batista. Sexualidade criminalizada: prostituição, lenocínio e outros delitos - São Paulo 1870/1920. Revista Brasileira de História, São Paulo, v. 18, n. 35, p. 1-38, 1998.

MOURA, Esmeralda Blanco Bolsonaro de. Meninos e meninas na rua: impasse e dissonância na construção da identidade da criança e do 
adolescente na República Velha. Revista Brasileira de História, São Paulo, v. 19, n. 37, 1999. Disponível em: 〈http://www.scielo.br〉 . Acesso em: 10 dez. 2003.

PESAVENTO, Sandra Jatahy. O cotidiano da República: elite e povo na virada do século. Porto Alegre: Ed. Universidade / UFRGS, 1990. . Visões do cárcere. Jeweb Editora Digita, 2003. 1 CD-Rom.

RAGO, Margareth. Do cabaré ao lar: a utopia da cidade disciplinar: Brasil 1890-1930. Rio de Janeiro: Paz e Terra, 1985.

SOCIEDADE BRASILEIRA DE PEDIATRIA. Guia de atenção frente aos maus-tratos na infância e adolescência. Rio de Janeiro: Editora SOB, 2001.

TINOCO, Luiz Antonio. Código Criminal do Império. Rio de Janeiro: Imprensa Nacional, 1886.

VARGAS, Anderson. Os subterrâneos de Porto Alegre: imprensa, ideologia autoritária e reforma social (1900 - 1919). Dissertação (Mestrado em História) - Universidade Federal do Rio Grande do Sul, Porto Alegre, 1992.

VIANNA, Adriana de Resende. O mal que se adivinha: polícia e menoridade no Rio de Janeiro (1910-1920). Rio de Janeiro: Arquivo Nacional, 1999.

WEBER, Beatriz Teixeira. As artes de curar: medicina, religião, magia e positivismo na república rio-grandense. Santa Maria: Ed. da UFSM; Bauru: EDUSC - Editora da Universidade do Sagrado Coração, 1999. 